The title for this Special Section is Origins of Children's Self-Views, edited by Eddie Brummelman and Sander Thomaes

\title{
Clear Self, Better Relationships: Adolescents' Self-Concept Clarity and Relationship Quality With Parents and Peers Across 5 Years
} \author{
Utrecht University \\ Jaap J. A. Denissen \\ Tilburg University
}

Andrik I. Becht, Stefanie A. Nelemans, Marloes P. A. Van Dijk, and Susan J. T. Branje

\author{
Pol A. C. Van Lier \\ Erasmus University
}

\author{
Wim H. J. Meeus \\ Utrecht University and Tilburg University
}

\begin{abstract}
This study examined reciprocal associations between adolescents' self-concept clarity (SCC) and their relationship quality with parents and best friends in a five-wave longitudinal study from age 13 to 18 years. In all, 497 adolescents (57\% boys) reported on their SCC and all informants (i.e., adolescents, both parents, and adolescents' best friends) reported on support and negative interaction. Within-person cross-lagged analyses provided systematic evidence for both parent effects and child effects, with the direction of effects being strongly dependent on the relational context. For example, higher maternal support predicted higher adolescent SCC, supporting a parent effects perspective, whereas higher SCC predicted lower paternal negative interaction, supporting a child effects perspective. Peer effects on adolescent SCC were not consistently found across adolescent and best friend reports.
\end{abstract}

Establishing a clear sense of self is a key developmental task of adolescence (Erikson, 1968). An important aspect of the self concerns the degree to which adolescents describe themselves in consistent ways and the extent to which they feel certain about themselves, also referred to as self-concept clarity (SCC; Campbell, 1990). Several theories on the self have emphasized the importance of interpersonal relationships with parents and best friends for the development of SCC in adolescence (see Chen, Boucher, \& Tapias, 2006 for an overview). At the same time, others have emphasized that adolescents' selfviews affect social relationships (Swann, ChangSchneider, \& Larsen McClarty, 2007) and that changes in clarity of the self may even precede

Data from the Research on Adolescent Development and Relationships (RADAR) study were used. RADAR has been financially supported by main grants from the Netherlands Organisation for Scientific Research (GB-MAGW 480-03-005) and Stichting Achmea Slachtoffer en Samenleving (SASS) to RADAR PI's, and from the Netherlands Organisation for Scientific Research to the Consortium on Individual Development (CID; 024.001.003).

Correspondence concerning this article should be addressed to Andrik I. Becht, Research Centre Adolescent Development, Utrecht University, P.O. Box 80 140, 3508 TC Utrecht, The Netherlands. Electronic mail may be sent to a.i.becht@uu.nl. changes in relationship quality during adolescence (Erikson, 1968). Importantly, because both perspectives have mainly been tested cross-sectionally and not longitudinally, it is difficult to substantiate claims regarding direction of effects. How adolescent SCC and quality of relationships with parents and best friends affect each other over time is therefore not well understood. Hence, the aim of the present study is to test different theoretical perspectives on the direction of effects between relationship quality and SCC across adolescence at the within-person level by using a multilevel framework cross-lagged panel model (Hamaker, Kuiper, \& Grasman, 2015).

\section{SCC in Adolescence}

SCC refers to structural aspects of the self rather than the evaluation of the content of the self, such as self-esteem (Campbell, Assanand, \& Di Paula,

(C) 2017 The Authors

Child Development (C) 2017 Society for Research in Child Development, Inc. All rights reserved. 0009-3920/2017/8806-0006

DOI: $10.1111 /$ cdev.12921 
2003). Individual differences in SCC have been found to be related to several indices of psychosocial functioning. For instance, higher levels of SCC have been positively related to identity development (Schwartz et al., 2011), and adolescents lacking clarity in their self-concept are at risk for developing higher levels of anxiety and depression (e.g., Campbell et al., 2003; Montague, Enders, Dietz, Dixon, \& Cavendish, 2008; Schwartz, Klimstra, Luyckx, Hale, \& Meeus, 2012; Van Dijk et al., 2014). The development of SCC may thus be considered as an important task of adolescence, emphasizing the importance to further understand potential antecedents and consequences of the development of SCC across adolescence.

\section{Parent and Best Friend Relationship Quality and SCC}

Developing an integrated sense of self can be a challenging task, especially during adolescence when changes occur in different life domains, such as education and personal relationships (Erikson, 1968; Furman \& Buhrmester, 1985; Koepke \& Denissen, 2012). Based on the assumption that the self is relational in nature and based on feedback from significant others, it has been suggested that adolescents' social relationships with close others, such as parents and best friends, might help them to establish a firm integrated self across multiple domains (Chen et al., 2006). bECAUSE relationship quality with parents and friends changes in adolescence, this raises the question whether linkages between relationship quality with parents and friends and SCC might also change across adolescence. For instance, parental influence decreases during adolescence, whereas friends become more important when adolescents grow older (Brown, 2004; De Goede, Branje, Delsing, \& Meeus, 2009). Moreover, friendship quality strongly increases during adolescence (De Goede, Branje, \& Meeus, 2009).

Theoretically, supportive interpersonal relationships can both foster adolescent SCC and evolve from adolescent SCC. Close supportive relationships with parents and friends may provide adolescents with opportunities and confidence to explore different aspects of the self and discuss self-relevant issues within their relationships, thereby allowing them to establish clear self-views (Grotevant \& Cooper, 1985). Supportive relationships might also confirm to adolescents that who they think they are and how they present themselves to others is accepted, resulting in less doubt about who they are or should be, and thus in higher levels of SCC. In the current study, the effect of interpersonal relationships on shaping adolescents SCC over time is referred to as a parent/peer effects perspective on development.

In contrast, adolescents' SCC might also affect the quality of interpersonal relationships over time. For example, Erikson's (1968) psychosocial theory holds that adolescents with a more coherent sense of self might be better able to engage in equal and mutual relationships without losing themselves in these relationships. If adolescents have an unclear self-concept, this could lead to submission to others and high dependency within relationships, undermining the development of mutual, high-quality relationships. In contrast, adolescents with high SCC are able to critically evaluate their relationships, give clear indications on the kind of relationships they want to have with peers and family, and invest in these relationships. In the current study, the effect of adolescents' SCC on interpersonal relationships over time is labeled as child effects perspective on development.

The parent/peer effects theoretical perspective has received empirical support in a limited number of longitudinal studies. For example, adolescentreported open communication with parents has been found to predict SCC over time across adolescence but not vice versa (Frijns \& Finkenauer, 2009; Van Dijk et al., 2014). Moreover, focusing on the intergenerational transmission of SCC, parental SCC has been found to predict adolescents' SCC but not vice versa (Crocetti, Rubini, Branje, Koot, \& Meeus, 2016). To the best of our knowledge, no longitudinal studies have investigated whether adolescents' SCC predicted relationship quality with parents and friends.

\section{The Present Study}

The first aim of this study was to investigate the direction of effects between SCC and relationship quality with parents and best friends. Our second and related aim was to investigate whether the strength of associations between relationship quality with peers and parents and SCC changes over time. To examine these two aims, we applied a multilevel type cross-lagged panel model (see Hamaker et al., 2015) using a 5-year multi-informant design covering early to late adolescence. In doing so, we were able to separate the between-person level from the within-person level associations between SCC and relationship quality with parents and best friends. In order to gain understanding how dynamic processes between relationship 
quality and SCC operate within individuals, regardless of the stable between-person differences in level of SCC and relationship quality, we need to study these linkages on a within-person level (Hamaker et al., 2015; Keijsers, 2016; Papp, 2004). Past studies, however, primarily examined associations without distinguishing the between-person level from the within-person level.

In addition, we add to previous research by taking a multi-informant approach to study relationship quality, which makes it possible to examine internal replication of associations within the same relationship dyad across informants (e.g., across mother and adolescent reports). Furthermore, to examine consistency in parent/peer effects and child effects across informants, a multi-informant approach enabled us to investigate whether adolescents just think they have better relationships with close others when their SCC is or becomes higher, or whether these others also experience them as better relationship partners. Indeed, it has been found that perceptions of relationship quality differ substantively when different reporters (e.g., parents vs. adolescents) report on the quality of the same relationship dyad (Branje, van Aken, \& van Lieshout, 2002). Hence, both adolescents and relationship partners provide unique views on the relationship quality (De Los Reyes \& Ohannessian, 2016).

We included daily diary assessments of SCC in order to minimize retrospection artifacts. That is, because with daily diaries we were relying less on adolescents' memories compared to when adolescents' SCC would have been assessed annually. Indeed, daily assessments have been found to be more reliable indicators relative to assessments with larger time intervals (Burk, Denissen, Van Doorn, Branje, \& Laursen, 2009). Based on theoretical models and limited longitudinal empirical studies, we predicted bidirectional longitudinal associations between social relationships and SCC. Specifically, we hypothesized that social relationships both shape SCC (i.e., referred to as a parent/peer effect) and are shaped by SCC (i.e., child effect). In order to gain a comprehensive understanding how different dimensions of relationship quality were related to SCC, we investigated both support and negative interaction within close interpersonal relationships.

\section{Method}

\section{Participants}

This study used data from 497 adolescents $(57 \%$ boys, $M_{\text {age }} \mathrm{T}_{1}=13.03, S D=0.46$ ), their mothers $\left(n=495, M_{\text {age }} \mathrm{T}_{1}=44.41, S D=4.46\right)$, their fathers $\left(n=446, \quad M_{\text {age }} \mathrm{T}_{1}=46.74, S D=5.10\right)$, and their same-sex best friend $\left(n=447,56 \%\right.$ boys, $M_{\text {age }}$ $\mathrm{T}_{1}=13.17, S D=0.84$ ), resulting in a total of 1,885 respondents. Study data are part of the young cohort of the ongoing longitudinal project Research on Adolescent Development and Relationships (RADAR-Y). Adolescents were recruited from central and western regions of the Netherlands. Based on parents' job level, most adolescents came from medium to high socioeconomic status (SES) families (87.9\%). The majority of adolescents classified themselves as being Dutch (94.8\%). Most adolescents indicated that they were living with both of their biological parents $(84.7 \%)$, or with their mother $(8.2 \%)$, with the rest living in a different family constellation (e.g., with their father or with one biological parent and one stepparent). Missing value analyses indicated that over time, $88.3 \%$ of the adolescent reports, $91.4 \%$ of mother reports, $82.9 \%$ of father reports, and $84.3 \%$ of best friend reports were completed. Little's missing completely at random (MCAR) test revealed that the pattern of missing values could be considered at random with a normed chi-square $\left(\chi^{2} / d f\right)$ of 1.36 , $1.12,1.54$, and 1.40 for adolescent, mother, father, and best friend reports, respectively, indicating that it is unlikely that our findings were biased as a result of missing values. Hence, missing data were handled in Mplus 7.31 (Muthén \& Muthén, 1998-2012) using full information maximum likelihood.

\section{Procedure}

The current study used data from five waves of RADAR-Y, with subjects being followed from ages 13 to 18 years. Adolescents participated in 15 measurement weeks (three online assessment weeks in each of the 5 years, separated by a 3-month interval), in which they filled out an online questionnaire tapping into their SCC for 5 days in a row (i.e., Monday through Friday), resulting in 75 assessments of SCC. The initial Internet assessment week (T1) took place in June, the second assessment (T2) took place 3 months later in September and T3 took place in December. This same assessment interval was used across the 5 years. Adolescents, their parents, and the best friend further reported on their relationship quality across five annual questionnaire assessments. The target adolescents nominated their best friend. Next, target adolescents were asked to invite their best friend and to provide contact information of his or her best friend. The first annual assessment took place 3 months before the first online assessment. All 
participants signed an informed consent form. The medical ethical committee of the University Medical Center Utrecht has approved the RADAR study.

Sample attrition was low across 5 years, with $85.1 \%$ of adolescents who participated in the 1st year still participating in the 5th year. We conducted attrition analyses by comparing the group of adolescents that dropped out over the course of the study with the group of adolescents that was still participating. No significant differences were found with regard to distribution of boys and girls between these groups, $\chi^{2}(1)=0.26, p=.61, \varphi=.23$. Similarly, no differences on T1 level of SCC were found between these groups, $F(1,474)=2.26$, $p=.13$, partial $\eta^{2}=.01$. However, adolescents who dropped out across the study were more likely to come from lower SES families, $\chi^{2}(1)=13.76$, $p=.00, \varphi=.17$, and were slightly older, $F(1$, $474)=14.22, p<.001$, partial $\eta^{2}=.03$.

\section{Measures}

\section{Daily SCC}

Adolescents reported on their SCC on a daily basis using a single-item measure of SCC, which was derived from the full Self-Concept Clarity Scale (Campbell et al., 1996): Today, I often wondered what kind of person I really am $(1=$ totally agree, $5=$ totally disagree). To establish reliability of this single-item scale, we used the procedure developed by Heise (1969). In this procedure, the reliability of a singleitem scale is assessed with an estimate of the testretest reliability using the following formula: $(r x x=(r 12 \times r 23) / r 13)$, which separates true change from measurement error. Because there were three measurement weeks in each year with 5 days each, we computed three Heise estimates per week. For the single SCC item, the mean Heise reliability ranged from 0.57 to 0.63 across 5 years, consistent with previous reports on a single-item version of SCC (Schwartz et al., 2011). Confirmatory factor analyses on the full SCC questionnaire (Campbell et al., 1996) revealed that the item, I often wonder what kind of person I really am, had high factor loadings (i.e., ranging between 0.76 and 0.82 across five waves) on the total SCC factor. Hence, we slightly adapted this original item to make it suitable to assess SCC on a daily basis (i.e., Today, I often wondered what kind of person I really am). Further supporting construct validity, the single-item SCC correlated significantly with the full SCC annual measure in our study, with correlations between $r=.36$ and $r=.47, p s<.001$, across five waves. In the analyses, we used the mean SCC score of the three online assessment weeks within each year, resulting in 5 yearly SCC scores with higher scores representing higher SCC.

\section{Relationship Quality}

In the current study, we focused on two key dimensions of close interpersonal relationships in adolescence, being support and negative interaction. Both support and negative interactions have been found to be important dimensions that tap into different aspects of adolescents' relationship quality with their mothers, fathers, and best friend (De Goede, Branje, Delsing, et al., 2009). Quality of the adolescent-mother, adolescent-father, and adolescent-best friend relationships was assessed across five annual measurement waves using the support and negative interaction subscales of the shortened Network of Relationship Inventory (Furman \& Buhrmester, 1985). Both the support scale (eight items, example item of mother-reported support: How much do you really care about your child) and the negative interaction scale (six items, example item for the adolescent-best friend relationship: Do you and your best friend get on each other's nerves?) were rated on a 5-point Likert scale $(1=$ a little or not at all, 5 =more is not possible). Across five waves, Cronbach's alphas of the support scale ranged from .90 to .92 for mother and father reports, from .80 to .85 for best friend reports, and from .87 to .95 for adolescent reports. Concerning the negative interaction scale, Cronbach's alphas ranged from .71 to .75 for mother reports, from .76 to .78 for father reports, from .82 to .90 for best friend reports, and from .78 to .90 for adolescent reports.

\section{Statistical Analyses}

To investigate whether linkages between relationship quality with parents and best friends and SCC pertain to actual within-person processes, we applied a random intercept cross-lagged panel model (Hamaker et al., 2015). This multilevel modeling approach is different from regular crosslagged panel modeling by including a random intercept for each construct (i.e., adolescents' SCC as well as parents' and best friends' relationship quality) to capture stable individual differences between adolescents. That is, for each construct the individual has an expected score that is based on the sample mean across time and the individual stable trait factor (i.e., the random intercept). Next, we created a latent variable for each of the 
observed variables by regressing the observed score on its own latent factor. Moreover, we constrained the variance of the observed variables to zero. Therefore, all the variance of these observed scores was captured in the within-person and betweenperson latent factors. This statistical procedure shifts the interpretation of the parameters from a between-person level to a within-person level. For example, stability paths can be interpreted as the extent to which an individual's deviation from his or her expected score can be predicted by individual's prior deviation from his or her own score. Similarly, the cross-lagged parameter reflects whether year-to-year fluctuations relative to their own expected score in one variable can be predicted by an individual's deviation from his or her own expected score in another variable 1-year earlier (Hamaker et al., 2015; Keijsers, 2016). A detailed description of the equations of this random intercept cross-lagged panel model is provided by Hamaker et al. (2015). An additional advantage of a within-person modeling approach is that all stable (unmeasured) confounding variables are controlled for (e.g., personality traits). Until now, it remained unclear whether associations between SCC and relationship quality were also present at the within-person level. Indeed, it has been found that effects that are present at the between-person level can be unrelated to withinperson effects (Hamaker et al., 2015), and betweenperson based estimates are often uninformative for predicting associations between variables at the within-person level (Molenaar \& Campbell, 2009).

To investigate the direction of effects between relationship quality with parents and best friends and adolescent SCC, we tested a fully constrained baseline model in which all parameters were constrained to be equal across time. Specifically, we included $\mathrm{T}_{1}$ correlations, 1-year stability paths for all constructs, within-time correlations between the relationship quality variables at $\mathrm{T}_{2-5}$ and cross-lagged parent/peer effects from parental and peer quality of relationship to SCC 1 year later, and child effects from adolescents' SCC to parental and peer quality of relationships. To investigate whether changes occur in the strength of the relationships between relationship quality with parents and best friends and SCC, we compared our baseline model to models in which all paths of interest (i.e., cross-lagged paths) were freely estimated across time. Absolute model fit was evaluated using the comparative fit index (CFI), the root mean square error of estimation (RMSEA), and the standardized root mean square residual (SRMR). Fit indices were considered sufficient with CFI $>0.90$,
RMSEA $<0.08$, and SRMR $<0.08$ (Byrne, 2012). For model comparison, we used the Satorra-Bentler chisquare $\left(\mathrm{S}-\mathrm{B} \chi^{2}\right)$ difference test, because we estimated our models using the maximum likelihood estimation with robust standard errors (i.e., MLR) to account for non-normal distributions (Muthén \& Muthén, 1998-2012).

In our models, we distinguished between adolescents' perceived quality of the relationship with their mother, father, and best friend, and the perceptions of mothers, fathers, and best friends for the quality of this relationship. To this end, we ran 4- to 5 -year longitudinal random intercept cross-lagged panel models for adolescents' perceptions of relationship quality (i.e., Model 1: adolescent-reported support from mother, adolescent-reported support from the best friend, and adolescent-reported SCC; Model 2: adolescent-reported support from father, adolescent-reported support from the best friend, and adolescent-reported SCC; Model 3: adolescentreported negative interaction with mother, adolescent-reported negative interaction with the best friend, and adolescent-reported SCC; Model 4: adolescent-reported negative interaction with father, adolescent-reported negative interaction with the best friend, and adolescent-reported SCC). Next, we ran four models including the relational partners as informant of relationship quality (i.e., Model 5: mother-reported support, best friend-reported support, and adolescent-reported SCC; Model 6; fatherreported support, best friend-reported support, and adolescent-reported SCC; Model 7: mother-reported negative interaction, best friend-reported negative interaction, and adolescent-reported SCC; Model 8; father-reported negative interaction, best friendreported negative interaction, and adolescentreported SCC). Figure 1 displays the analytical model we used to investigate within-person linkages between relationship quality and SCC.

\section{Results}

Means and standard deviations of all study variables across waves and correlations between study variables at the first wave are presented in Tables S1 and S2, respectively.

\section{Relationship Quality and SCC}

Fit of our fully constrained time-invariant baseline models was good: $\mathrm{S}-\mathrm{B} \chi^{2}(90)$ ranged between 97.05 and 148.94, CFI between 0.98 and 1.00, RMSEA between 0.01 and 0.04, and SRMR between 


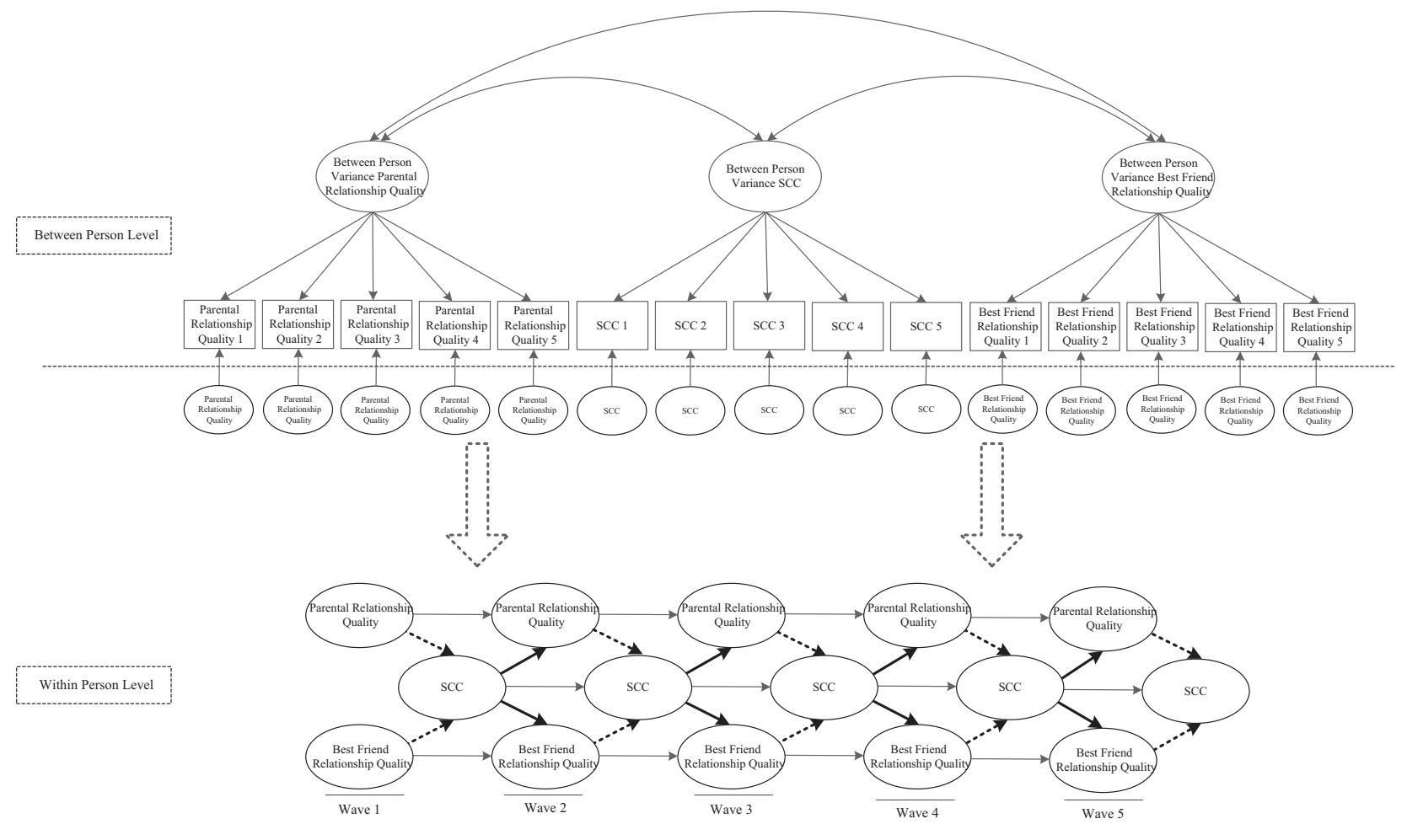

Figure 1. Analytical within-person path model that was used to investigate within-person linkages between relationship quality and self-concept clarity. SCC = self-concept clarity. Child effects are shown in solid lines and socialization effects in dashed lines. For reasons of presentation, the between-person level part (top panel) and within-person level part (bottom level panel) of the model are visually presented separately. However, for the analyses we estimated all parameters into one model at the same time.

0.04 and 0.08 . To investigate our hypothesis that changes occur across adolescence in the strength of the associations between relationship quality with best friends and parents on the one hand and SCC on the other hand, we tested whether cross-lagged effects could be freely estimated across time. However, freeing the cross-lagged effects across time did not significantly improve model fit for adolescent-, mother-, father-, and best friend-reported relationship quality predicting SCC, $\Delta \mathrm{S}-\mathrm{B} \chi^{2}(4)$ ranging between 1.78 and 8.33 , all $p s>.08$, and neither for SCC predicting perceived and mother-, father-, and best friend-reported relationship quality, $\Delta \mathrm{S}-\mathrm{B} \chi^{2}(3)$ ranged between 0.23 and 6.71, all $p s>.09$. Hence, for reasons of parsimony we kept all model parameters constrained to be time invariant. Thus, these findings do not support our expectations that developmental changes occur in the strength of associations between parents' and best friends' relationship quality and SCC across adolescence. Results of the models are presented in Table 1. Paths of the models that were not directly related to our research aim can be found in Supporting Information. These include 1-year within-person stability paths, which are presented in Table S3.
Concurrent within-person associations and correlations between the trait-like differences in relationship quality and SCC can be found in Data S1.

\section{Relationship Quality and SCC: Parent/Peer Effects}

Across parental, best friend, and adolescent reports, 4 of 12 possible cross-lagged effects that were significant were consistent with a parent/peer effects model. Within-person increase in level of perceived maternal and paternal support predicted an increase in adolescents' SCC, $\beta=.08$ to $.10,1$ year later. Also, mother-reported support predicted within-person increase in adolescents' SCC one wave later, $\beta=.05$ to .07 . In addition, perceived paternal negative interaction was associated with a later decrease in SCC, $\beta=-.05$ to -.07 . Hence, consistent across reporters, the quality of the relationships between adolescents and their mothers predicted an increase in adolescents' SCC. Three of the four parent effects were adolescent reported. We found no evidence for relationships with best friends shaping adolescents' SCC (i.e., no peer effects were found).

Additionally, we investigated whether crosslagged effects from parental relationship quality to 
Table 1

Standardized Cross-Lagged Paths ${ }^{a}$ for Relationship Quality and Self-Concept Clarity

\begin{tabular}{|c|c|c|}
\hline & Child effects $^{\mathrm{b}}$ & Parent/peer effects ${ }^{c}$ \\
\hline \multicolumn{3}{|l|}{ Other-reported support } \\
\hline Mother about adolescent & $.11^{*} / .13^{*} / .13^{*} / .11^{* *}$ & $.07^{*} / .06^{*} / .05^{*} / .05^{*} / .07^{*}$ \\
\hline Father about adolescent & $.03 / .04 / .04 / .04$ & $.01 / .01 / .01 / .01 / .01$ \\
\hline Best friend about adolescent & $-.00 /-.00 /-.00 /-.00$ & $-.03-.03 /-.03 /-.03 /-.03$ \\
\hline \multicolumn{3}{|l|}{ Adolescent-reported support } \\
\hline Adolescent about mother & $.04 / .05 / .04 / .05$ & $.08^{* *} / .08^{* *} / .08^{* *} / .09^{* *} / .09^{* *}$ \\
\hline Adolescent about father & $.11^{*} / .13^{*} / .13^{*} / .12^{* *}$ & $.09^{*} / .09^{*} / .09^{*} / .09^{*} / .10^{*}$ \\
\hline Adolescent about best friend & $.08^{*} / .09^{*} / .09^{*} / .09^{*}$ & $-.02 /-.01 /-.02 /-.02 /-.02$ \\
\hline \multicolumn{3}{|l|}{ Other-reported neg. int. } \\
\hline Mother about adolescent & $-.09^{* *} /-.11^{* *} /-.10^{* *} /-.10^{* *}$ & $-.03 /-.03 /-.03 /-.03 /-.03$ \\
\hline Father about adolescent & $-.08^{* *} /-.09^{* *} /-.09^{* *} /-.09^{* *}$ & $-.04 /-.04 /-.04 /-.04 /-.04$ \\
\hline Best friend about adolescent & $-.05 /-.05 /-.05 /-.06$ & $-.01 /-.01 /-.02 /-.02 /-.02$ \\
\hline \multicolumn{3}{|l|}{ Adolescent-reported neg. int. } \\
\hline Adolescent about mother & $-.03 /-.03 /-.03 /-.03$ & $-.03 /-.03 /-.03 /-.03 /-.04$ \\
\hline Adolescent about father & $-.13^{* *} /-.13^{* *} /-.13^{* *} /-.11^{* *}$ & $-.05^{*} /-.06^{*} /-.06^{*} /-.06^{*} /-.07^{*}$ \\
\hline Adolescent about best friend & $-.08^{*} /-.09^{*} /-.08^{*} /-.09^{*}$ & $-.02 /-.02 /-.02 /-.02 /-.02$ \\
\hline
\end{tabular}

Note. Significant cross-lagged effects across Waves 1 through 5 are separated by a slash. Neg. int. = negative interaction; SCC $=$ selfconcept clarity. ${ }^{\mathrm{a}}$ On average, the cross-lagged relationships were 6 months later. ${ }^{\mathrm{b}}$ Child effects refer to the cross-lagged effects when changes in adolescents' SCC affect relationship quality. 'Parent/peer effects refer to the cross-lagged effects when changes in relationship quality affect SCC.

$* p<.05 . * * p<.01$.

SCC differed for boys and girls. Results suggested two (of eight) significant moderation effects: Increasing mother-reported support predicted increasing SCC for boys, but not for girls, $\Delta \mathrm{S}-\mathrm{B} \chi^{2}(1)=4.36$, $p=.03$. Similarly, increasing mother-reported negative interaction predicted decreasing SCC for boys but not for girls, $\Delta \mathrm{S}-\mathrm{B} \chi^{2}(1)=8.97, p=.00$. For the other parent effects, freeing these cross-paths for boys and girls did not significantly improve model fit, $\Delta \mathrm{S}-\mathrm{B} \chi^{2}(1)$ ranging between -1.43 and 1.52 , all $p s>.22$, suggesting no significant differences between boys and girls in these associations.

\section{Relationship Quality and SCC: Child Effects}

Across multiple informants, 7 of 12 possible crosslagged effects that were significant were consistent with child effects model. When adolescents reported increasing SCC, they also reported increasing paternal support, $\beta=.11$ to .13 , as well as increasing perceived support from the best friend, $\beta=.08$ to .09 , in the subsequent wave. In addition, an increase in SCC boosted mother-reported support, $\beta=.11$ to .13 . Moreover, increasing adolescents' SCC predicted less perceived paternal negative interaction, $\beta=-.11$ to -.13 , and less perceived negative interaction with the best friend, $\beta=-.08$ to -.09 . Finally, an increase in SCC predicted less mother-reported negative interaction, $\beta=-.09$ to -.11 , as well as father- reported negative interaction, $\beta=-.08$ to -.09 . In sum, consistent across different informants, an increase in adolescents' SCC predicted parent-child relationship quality. Concerning hypothesized linkages between relationship quality with the best friend and SCC, we only found support in the selfreported models. However, these child effects were not confirmed by the best friends themselves.

We also tested whether cross-lagged effects between best friend relationship quality and SCC differed for adolescents who had stable best friends $(n=172)$ across 5 years compared to adolescents who had unstable friends or stable friends for $<5$ years $(n=325)$. Results did not suggest any moderation by friendship stability. That is, freeing the cross-paths for stable versus unstable friendships did not significantly improve model fit, $\Delta S$ $\mathrm{B} \chi^{2}(1)$ ranging between 0.00 and 2.17, all $p \mathrm{~s}>.14$.

\section{Discussion}

The current 5-year longitudinal multi-informant study investigated the directional nature between relationship quality with parents and the best friend and adolescents' SCC, using a multilevel framework cross-lagged panel model. Overall, our longitudinal findings supported bidirectional effects between quality of relationships and clarity of 
adolescents' self-concept. However, we found somewhat more support for child effects than parent/ peer effects. Yet, the direction of these effects was strongly dependent on the relational context. For instance, increasing support from mother predicted higher levels of adolescents' SCC. However, increasing adolescents' SCC predicted less negative interaction with father.

\section{Relationship Quality and SCC: Child Effects}

We found consistent support for child effects in the longitudinal association between adolescent SCC and interpersonal relationship quality across different reporters. Specifically, adolescents' increasing SCC predicted a decrease in mother- and father-reported negative interaction, as well as adolescent-reported negative interaction with the father 1 year later. In addition, an increase in adolescents' SCC fostered mother-reported support. Importantly, all within-person longitudinal cross-lagged paths could be constrained to be time invariant, suggesting that these associations appear to be similar from early to late adolescence. In sum, adolescents' SCC seems to be an important predictor of the quality of relationships within the family context across adolescence. These results fit with an increasing body of longitudinal studies showing that self-development is a strong predictor for quality of family relationships (Crocetti, Branje, Rubini, Koot, \& Meeus, 2017) as well as romantic relationships (Beyers \& Seiffge-Krenke, 2010) across adolescence. Note that child effects were particularly prominent in parent reports (compared to parent/peer effects). When considering adolescent reports only, child effects and parent effects were more balanced.

Moreover, our study results are consistent with Erikson's (1968) theoretical model, which predicts that when adolescents have a clear integrated selfconcept this paves the way for them to develop high-quality interpersonal relationships with close others. During this developmental period, adolescents are also striving for increased autonomy and individuation, in which relationships with their parents become more egalitarian (Grotevant \& Cooper, 1985; Koepke \& Denissen, 2012; Laursen \& Collins, 2009). Those adolescents with increasing self-certainty and feeling significant (Adams \& Marshall, 1996) might be more likely to invest in the quality of relationships and show relationship attachment without having to fear ego loss (Erikson, 1968).

Concerning best friend relationships, adolescents' SCC also affected relationship quality with the best friend, but findings were somewhat more complex than concerning the parent-adolescent relationship. When adolescents' SCC increased, they perceived an improvement in relationship quality with their best friends 1 year later, indicated by higher perceived support and lower perceived negative interaction. However, adolescents' SCC was not affecting relationship quality as reported by the best friend. One possible explanation for this finding is that the salience of relationships with best friends in forming mental representations of the self might be lower during adolescence compared to the salience of parent-child relationships. Alternatively, the fact that these associations only existed within the perception of adolescents could also be a result of common method variance, because adolescents reported on the relationship quality with the best friend as well as on their SCC.

\section{Relationship Quality and SCC: Parent/Peer Effects}

We also found empirical support for relationship quality with parents predicting adolescents' SCC. These parent effects were most consistently present when considering adolescent-reported relationship quality with their parents. We did not find support for relationship quality with the best friend shaping adolescents' SCC. Concerning parent effects, a warm and supportive relationship with their mother predicted an increase in adolescents' SCC, which was consistent across both mother reports and adolescent reports. In addition, adolescent-perceived support from their father predicted increasing SCC, but father-reported support was not related to adolescents' SCC. This finding might indicate that support from mothers may be especially important for boosting SCC, compared to support from fathers. Consistent with this finding, it has been found that mothers are particularly involved in providing socioemotional support to their adolescents, relative to fathers (Smetana, Campione-Barr, \& Metzger, 2006). Therefore, within a supportive adolescent-mother relationship, adolescents may feel more comfortable to express issues and thoughts about their self-concept, which may boost adolescents' SCC over time (Smetana et al., 2006). Moreover, mothers tend to spend more time in daily interactions with their adolescents, which may also provide adolescents with more chances to enhance their SCC within a mutually warm and nurturing mother-adolescent relationship, compared to fathers (Dusek \& McIntyre, 2003).

In contrast, adolescents' perception of increased negative interaction with their fathers predicted 
decreases in SCC 1 year later, but the perception of maternal negative interaction did not affect adolescents' SCC. This finding may in part be explained by different roles that fathers and mothers play in shaping adolescents' SCC. That is, although mothers appear to provide more emotional support, fathers are more task oriented and more involved in disciplining their child (e.g., Smetana et al., 2006). Therefore, especially when fathers increase in disciplining their child, accompanied by increasing negative interactions, this might lower adolescents' SCC. Indeed, adolescents who reported increasing regulation by their fathers, reported lower self-concept as well (e.g., Litovsky \& Dusek, 1985).

In sum, our findings add to the literature by showing differential influences of mothers and fathers in shaping adolescents' SCC depending on the dimensions of relationship quality. Our results are consistent with theoretical models that have emphasized the important role of parents in shaping adolescents' self-concept over time (Chen et al., 2006; Grotevant \& Cooper, 1985). Our results supported these theoretical models by showing that increasing support from mothers (both mother and adolescent reported) fostered adolescents' SCC. Additional findings revealed that parent/peer effects were most prominent according to adolescents' perceptions but less when considering parent and best friend reports. Future studies are needed to examine the replicability of these findings.

In contrast to parent effects, we consistently found no support for peer effects on adolescents' SCC in both adolescent and best friend reports. Although the influence of peers has been established for shaping various domains of adolescent functioning, such as aggressive behavior (Dishion \& Tipsord, 2011) and school motivation (Ryan, 2000), we suggest that peers might serve a different function for adolescents' SCC development. Instead of peer effects on SCC during adolescence, the self-concept might serve to develop and maintain high-quality relationships with peers. This function is consistent with Erikson's (1968) notion that when adolescents have established a clear sense of self, they are also able to evaluate their relationships, indicate the type of relationships they want to have, and invest in these relationships.

In sum, across multiple informants, we found that adolescents' SCC affected their social relationships as well as social relationships affecting their SCC. These findings applied particularly to parentadolescent relationships. However, whether child effects or parent/peer effects were found was largely dependent on the relational context. At a more general level, however, we identified somewhat more child effects in our study compared to parent/peer effects, which may reflect adolescents' increasing maturation in the organization of the self and increasing agency in shaping relationships. Similarly, a recent overview of multiple longitudinal adolescent studies across the world reported systematic evidence that adolescents influence parent-adolescent, parenting and peer-adolescent relationships. Less systematic evidence was found for the reverse pattern (Meeus, 2016).

\section{Strengths and Limitations}

This study is characterized by several strengths. First, our 5-year multi-informant design enabled us to investigate the longitudinal direction of effects between relationship quality with parents and friends and SCC across the entire period of adolescence. Second, by including both mother-, father-, and best friend-reported quality of relationships with the adolescent, the current study was able to identify differential associations between different relationship partners and SCC (Dusek \& McIntyre, 2003). Third, the current study investigated withinperson longitudinal associations by using a multilevel framework cross-lagged panel model (Hamaker et al., 2015). This type of modeling has been strongly suggested to study actual within-person linkages. That is, by differentiating the betweenperson level from the within-person level, we were able to analyze how changes in the quality of relationships within-families, and within-friendship dyads were related to adolescents' SCC (Hamaker et al., 2015; Keijsers, 2016). In addition to these strengths, the current study also has some limitations. First, the sample included primarily Dutch adolescents from relatively high SES families, which raises questions to what extent our findings can be replicated in lower SES samples. However, although there might exist mean-level differences in the amount of negative interaction and support between adolescents from different levels of family SES, future research is needed to investigate whether longitudinal associations are also different for adolescents with lower versus higher SES backgrounds. Second, our main aim was to investigate bidirectional associations between quality of relationships with the parents versus the best friend on the one hand and adolescents' SCC on the other. However, due to model complexity, we were not able to control for potentially overlapping effects of both quality of relationships with mothers and fathers on adolescents' SCC. Our models and Stolz, Barber, and Olsen's (2005) analyses suggest that mothers 
and fathers show unique contributions to adolescents' development; future research should further investigate to what extent mothers and fathers have differential parental effects on adolescents' SCC. Third, although we investigated two key dimensions of relationship quality, other relationship dimensions of the parent-adolescent and friendship dyads should be included in future work to test how they are related to the development of the self across adolescence. For instance, parental open communication with their adolescents has been found to predict change in SCC across adolescence (Van Dijk et al., 2014). Future research should study different relational aspects of the friendship dyads to further investigate linkages between friendship quality and adolescents' SCC.

\section{Conclusion}

Despite these limitations, the current study supported bidirectional associations between adolescents' relationship quality with their parents and best friend and the development of clear self-views. Specifically, direction of effects were largely dependent on the relational context (e.g., adolescent-father vs. adolescent-mother relationship dyad), such that close relationships with mothers affected adolescent's SCC and changes in adolescents' SCC were a strong predictor of change in relationship quality with fathers. We investigated these longitudinal associations on a within-person level using multiple informants of relationship quality. Future research should further investigate differential associations between adolescents' self-views and relationships across multiple relationship partners.

\section{References}

Adams, G. R., \& Marshall, S. (1996). A developmental social psychology of identity: Understanding the person in context. Journal of Adolescence, 19, 1-14. https://doi. org/10.1006/jado.1996.0041

Beyers, W., \& Seiffge-Krenke, I. (2010). Does identity precede intimacy? Testing Erikson's theory on romantic development in emerging adults of the 21st century. Journal of Adolescent Research, 25, 387-415. https://doi. org/10.1177/0743558410361370

Branje, S. J., van Aken, M. A., \& van Lieshout, C. F. (2002). Relational support in families with adolescents. Journal of Family Psychology, 16, 351-362. https://doi. org/doi.org/10.1037/ / 0893-3200.16.3.351

Brown, B. B. (2004). Adolescents' relationships with peers. In R. M. Lerner \& L. Steinberg (Eds.), Handbook of adolescent psychology (pp. 363-394). Hoboken, NJ: Wiley. https: / / doi.org/10.1002/9780471726746
Burk, W. J., Denissen, J., Van Doorn, M. D., Branje, S. J., \& Laursen, B. (2009). The vicissitudes of conflict measurement: Stability and reliability in the frequency of disagreements. European Psychologist, 14, 153-159. https: / / doi.org/10.1027/1016-9040.14.2.153

Byrne, B. M. (2012). Structural equation modeling with Mplus: Basic concepts, applications, and programming. New York, NY: Routledge.

Campbell, J. D. (1990). Self-esteem and clarity of the selfconcept. Journal of Personality and Social Psychology, 59, 538-549. https://doi.org/10.1037/0022-3514.59.3.538

Campbell, J. D., Assanand, S., \& Di Paula, A. (2003). The structure of the self-concept and its relation to psychological adjustment. Journal of Personality, 71, 115-140. https: / / doi.org/10.1111/1467-6494.t01-1-00002

Campbell, J. D., Trapnell, P. D., Heine, S. J., Katz, I. M., Lavallee, L. F., \& Lehman, D. R. (1996). Self-concept clarity: Measurement, personality correlates, and cultural boundaries. Journal of Personality and Social Psychology, 70, 141-156. https:/ / doi.org/10.1037/0022-3514.70.6.1114

Chen, S., Boucher, H. C., \& Tapias, M. P. (2006). The relational self revealed: Integrative conceptualization and implications for interpersonal life. Psychological Bulletin, 132, 151-179. https://doi.org/10.1037/0033-2909.132.2. 151

Crocetti, E., Branje, S., Rubini, M., Koot, H., \& Meeus, W. (2017). Identity processes and parent-child and sibling relationships in adolescence: A five-wave multi-informant longitudinal study. Child Development, 88, 210228. https:/ / doi.org/10.1111/cdev.12547

Crocetti, E., Rubini, M., Branje, S., Koot, H. M., \& Meeus, W. (2016). Self-concept clarity in adolescents and parents: A six-wave longitudinal and multi-informant study on development and intergenerational transmission. Journal of Personality, 84, 580-593. https://doi. org/10.1111/jopy.12181

De Goede, I. H., Branje, S. J., Delsing, M. J., \& Meeus, W. H. (2009). Linkages over time between adolescents' relationships with parents and friends. Journal of Youth and Adolescence, 38, 1304-1315. https://doi.org/10. 1007/s10964-009-9403-2

De Goede, I. H., Branje, S. J., \& Meeus, W. H. (2009). Developmental changes in adolescents' perceptions of relationships with their parents. Journal of Youth and Adolescence, 38, 75-88. https://doi.org/10.1007/s10964008-9286-7

De Los Reyes, A., \& Ohannessian, C. M. (2016). Introduction to the special issue: Discrepancies in adolescent-parent perceptions of the family and adolescent adjustment. Journal of Youth and Adolescence, 1-16, https://doi.org/ 10.1007/s10964-016-0533-z

Dishion, T. J., \& Tipsord, J. M. (2011). Peer contagion in child and adolescent social and emotional development. Annual Review of Psychology, 62, 189-214. https://doi. org/10.1146/annurev.psych.093008.100412

Dusek, J. B., \& McIntyre, J. G. (2003). Self-concept and self-esteem development. In G. R. Adams \& M. D. Berzonsky (Eds.), Blackwell handbook of adolescence (pp. 290- 
309). Malden, MA: Blackwell. https://doi.org/10.1002/ 9780470756607.ch14

Erikson, E. (1968). Identity, youth and crisis. New York, NY: Norton. https://doi.org/10.1126/science.161.3838.257

Frijns, T., \& Finkenauer, C. (2009). Longitudinal associations between keeping a secret and psychosocial adjustment in adolescence. International Journal of Behavioral Development, 33, 145-154. https://doi.org/10.1177/ 016502540809802054

Furman, W., \& Buhrmester, D. (1985). Children's perceptions of the personal relationships in their social networks. Developmental Psychology, 21, 1016. https://doi. org/10.1037/0012-1649.21.6.1016

Grotevant, H. D., \& Cooper, C. R. (1985). Patterns of interaction in family relationships and the development of identity exploration in adolescence. Child Development, 56, 415-428. https://doi.org/10.1111/j.1467-8624. 1985.tb00116.x

Hamaker, E. L., Kuiper, R. M., \& Grasman, R. P. (2015). A critique of the cross-lagged panel model. Psychological Methods, 20, 102-116. https:/ / doi.org/10.1037/a0038889

Heise, D. R. (1969). Separating reliability and stability in test-retest correlation. American Sociological Review, 34, 93-101. https: / / doi.org/10.2307/2092790

Keijsers, L. (2016). Parental monitoring and adolescent problem behaviors How much do we really know? International Journal of Behavioral Development, 40, 217-281. https://doi.org/10.1177/0165025415592515

Koepke, S., \& Denissen, J. J. A. (2012). Individuation and identity development in adolescence and emerging adulthood: Conceptual clarifications and an integrative model. Developmental Review, 32, 67-88. https://doi. org/10.1016/j.dr.2012.01.001

Laursen, B., \& Collins, W. A. (2009). Parent-child relationships during adolescence. In R. M. Lerner \& L. D. Steinberg (Eds.), Contextual influences on adolescent development: Vol. 2. Handbook of adolescent psychology (pp. 342). Hoboken NJ: Wiley. https://doi.org/10.1002/ 9780470479193.adlpsy002002

Litovsky, V. G., \& Dusek, J. B. (1985). Perceptions of child rearing and self-concept development during the early adolescent years. Journal of Youth and Adolescence, 14, 373-387. doi:10.1007/bf02138833

Meeus, W. (2016). Adolescent psychosocial development: A review of longitudinal models and research. Developmental Psychology, 52, 1969-1996. https://doi.org/10. $1037 /$ dev0000243

Molenaar, P. C., \& Campbell, C. G. (2009). The new person-specific paradigm in psychology. Current Directions in Psychological Science, 18, 112-117. https://doi.org/10. 1111/j.1467-8721.2009.01619.x

Montague, M., Enders, C., Dietz, S., Dixon, J., \& Cavendish, W. M. (2008). A longitudinal study of depressive symptomology and self-concept in adolescents. Journal of Special Education, 42, 67-78. https:/ /doi.org/10.1177/ 0022466907310544

Muthén, L. K., \& Muthén, B. O. (1998-2012). Mplus user's guide (7th ed.). Los Angeles, CA: Author.
Papp, L. M. (2004). Capturing the interplay among withinand between-person processes using multilevel modeling techniques. Applied and Preventive Psychology, 11, 115-124. https:/ / doi.org/10.1016/j.appsy.2004.09.002

Ryan, A. M. (2000). Peer groups as a context for the socialization of adolescents' motivation, engagement, and achievement in school. Educational Psychologist, 35, 101-111. https://doi.org/10.1207/S15326985EP3502_4

Schwartz, S. J., Klimstra, T. A., Luyckx, K., Hale, W. W., Frijns, T., Oosterwegel, A., . . Meeus, W. H. (2011). Daily dynamics of personal identity and self-concept clarity. European Journal of Personality, 25, 373-385. https: / / doi.org/10.1002/per.798

Schwartz, S. J., Klimstra, T. A., Luyckx, K., Hale, W. W., III, \& Meeus, W. H. J. (2012). Characterizing the selfsystem over time in adolescence: Internal structure and associations with internalizing symptoms. Journal of Youth and Adolescence, 41, 1208-1225. https://doi.org/ $10.1007 /$ s10964-012-9751-1

Smetana, J. G., Campione-Barr, N., \& Metzger, A. (2006). Adolescent development in interpersonal and societal contexts. Annual Review of Psychology, 57, 255-284. https:/ / doi.org/10.1146/annurev.psych.57.102904.190124

Stolz, H. E., Barber, B. K., \& Olsen, J. A. (2005). Toward disentangling fathering and mothering: An assessment of relative importance. Journal of Marriage and Family, 67, 10761092. https:// doi.org/10.1111/j.1741-3737.2005.00195.x

Swann, W. B., Jr., Chang-Schneider, C., \& Larsen McClarty, K. (2007). Do people's self-views matter? Self-concept and self-esteem in everyday life. American Psychologist, 62, 84-94. https://doi.org/10.1037/0003-066X362.2.84

Van Dijk, M. P., Branje, S., Keijsers, L., Hawk, S. T., Hale, W. W., III, \& Meeus, W. (2014). Self-concept clarity across adolescence: Longitudinal associations with open communication with parents and internalizing symptoms. Journal of Youth and Adolescence, 43, 1861-1876. https:/ /doi.org/10.1007/s10964-013-0055-x

\section{Supporting Information}

Additional supporting information may be found in the online version of this article at the publisher's website:

Table S1. Means and Standard Deviations (Between Parentheses) of Self-Concept Clarity and Adolescent, Mother, Father, and Best Friend Reports of Support and Negative Interaction

Table S2. Correlations Between Self-Concept Clarity and Relationship Quality for All Study Variables at $\mathrm{T} 1$

Table S3. One-Year Standardized Stability Paths for Self-Concept Clarity and Relationship Quality

Data S1. Concurrent Within-Person Associations and Correlations Between the Trait-Like Differences in Relationship Quality and SCC. 